\title{
The Effect of Job Seeker's Perceived Social Support on Job Search Needs: Focusing on the Mediating Effect of Communication Process
}

\author{
Tae-Jung Park ${ }^{1)}$, Sanguk Hong ${ }^{2)}$ \\ 구직자가 지각한 사회적 지지가 구직욕구에 미치는 영향 : \\ 의사소통 과정의 매개효과를 중심으로 \\ 박태정1), 홍상욱2)
}

\begin{abstract}
The purpose of this study is to grasp the mediating effect of the communication process on the effect of job seeker's perceived social support on job search needs. The study was conducted with 230 users of job centers in $\mathrm{OO}$ city, Gyeongsangbuk-do. As for the analysis method, frequency analysis, reliability analysis, descriptive statistics analysis, correlation analysis, and three-step median effect analysis used by Baron \& Kenny (1987) were performed using the SPSS program, and Sobel test was performed for statistical verification. As a result of the study, first, it was found that social support and communication of job center users influenced their job search needs. Second, as a result of analyzing the mediating effect of the communication process on the effect of social support of job center users on job search needs, the communication process showed a partial mediating effect on the effects of emotional support, information support, material support, and evaluation support on job search needs. This study is considered to be the basic data for the development of the communication promotion program that can increase job search behavior for job seekers by grasping the effects of job seekers' perceived social support on job search needs, and in particular, and revealing that communication has a mediating effect on social support and job search needs.
\end{abstract}

Keywords: Job Center Users, Job Seekers, Social Support, Job Search Needs, Communication

Received(June 9, 2020), Review Result(1st: July 31, 2020, 2nd: September 17, 2020), Accepted(October 28, 2020)

1) (Ph.D. course) 02838 Dept. Department of Family and Housing Graduate School, Yeungnam University, 280 Daehak-ro, Gyeongsan,Gyeongbuk, Korea

email: jobmap01@hanmail.net

2) (Professor, Corresponding Author) 02838 Dept. Department of Family and Housing Studies, Yeungnam University, 280 Daehak-ro, Gyeongsan, Gyeongbuk, Korea

email: Hong sanguk@yumail.ac.kr 


\section{The Effect of Job Seeker's Perceived Social Support on Job Search Needs: Focusing on the Mediating Effect of Communication Process}

요 약

본 연구의 목적은 구직자가 지각한 사회적 지지가 구직욕구에 미치는 영향에 있어서 의사소통 과정 의 매개효과를 파악하는 데 있다. 연구대상은 경상북도 $\mathrm{OO}$ 시의 고용센터 이용자 230명을 대상으로 조사하였다. 분석 방법은 SPSS 프로그램을 사용해 빈도 분석, 신뢰도 분석, 기술통계 분석, 상관 분석, Baron \& Kenny(1987)가 사용한 3단계 매개효과 분석을 실시하였으며, 통계적 검증을 위하여 Sobel test를 실시하였다. 연구결과 첫째, 구직자가 지각한 사회적 지지와 의사소통은 구직욕구에 영향을 주 는 것으로 나타났다. 둘째, 구직자가 지각한 사회적 지지가 구직욕구에 미치는 영향에 대해서 의사소 통 과정의 매개효과를 분석한 결과 정서적 지지, 정보적 지지, 물질적 지지, 평가적 지지가 구직욕구 에 미치는 영향에 대해서 의사소통 과정은 부분 매개 효과를 보이고 있는 것으로 나타났다. 본 연구 의 시사점은 구직자가 지각한 사회적 지지가 구직욕구에 미치는 영향을 파악하고, 특히 의사소통이 사회적 지지와 구직욕구에서 매개효과가 있음을 밝힘으로써 구직자에게 있어서 구직행동을 증가시킬 수 있는 의사소통 증진 프로그램 개발을 위한 기초자료가 될 것으로 사료된다.

핵심어: 구직자, 사회적 지지, 구직욕구, 의사소통 과정

\section{1. 서론}

\section{1 연구의 필요성}

현대 사회가 급변하면서 핵가족화와 고령인구의 증가로 인해 전통적인 가족기능의 쇠퇴, 사회적 응집력의 약화, 지역사회 공동체의 의미상실 등 다양한 사회문제들이 발생됨에 따라 심각한 사회 문제가 발생하고 있다. 현재에는 실업이 매우 중요한 요인이라 할 수 있다. 통계자료에 의하면 2016년 경제성장률은 2.8\%로 전년도 수준을 유지하였으며, 취업자 증가 역시 약 2,623만 명으로 전 년 대비 약 29만 명 증가(1.2\% 증가)에 그쳐 2010년 이후 가장 낮은 수준으로 증가하고 있다[1]. 이러한 경제성장과 일자리의 관계를 파악해 보면, 완만한 경기 회복에도 취업자 수의 증가세는 상 대적으로 낮아지고 있어 고용문제에 대한 심각성과 사회적 관심이 부각되고 있다. 최근 코로나19 로 인해 고용불안은 더욱 심각한 상황인데, 통계청에 따르면 2020년 2월 일시 휴직자는 전년 대비 $29.8 \%$ 증가한 618,000 명으로 10년 만에 가장 큰 증가세를 보였으며, 이러한 상황은 세계적인 추세 이다[2].

지속되는 고용불안 속에서 구직자의 심리적인 요인이 매우 중요한 요인으로 작용하는데, 구직자 자신이 취업을 하고자 하는 옥구가 있는지를 파악하고, 자신이 구직행동을 해나갈 수 있는 능력이 있다고 생각하는지에 대한 자신감 상승과 정서적 지지가 매우 중요한 것으로 나타났다[3]. 특히 구 직자들의 구직활동 적극성, 일자리에 대한 수용 자세 등의 구직욕구에 영향을 미치는 요인에 대한 연구 필요성이 제기되고 있다. 하지만 선행연구에서는 구직욕구 외에 구직효능감, 구직행동, 구직 의사, 진로 자기효능감, 진로 준비 행동 등의 다양한 용어로 혼용되어 사용되고 있으며, 구직욕구 에 영향을 미치는 요인들은 크게 심리적 요인, 환경요인, 개인요인 등 매우 다양하게 나타나고 있 다.

사회적 지지가 구직욕구에 미치는 영향에 대한 선행연구를 살펴보면, 중장년층의 구직자를 대상 
으로 한 연구에서 사회적 지지는 중장년 구직자의 구직행동에 긍정적인 영향을 미치는 것으로 나 타났으며, 특히 구직행동에는 정서적 지지와 정보적 지지가 영향을 미치는 것으로 분석되었다[4]. 이러한 연구결과를 통해 중장년층의 구직활동을 제고하기 위해서는 주변으로부터 심리적 지원이 필요함을 판단할 수 있다. 또한 경력단절 여성의 구직자를 대상으로 한 연구에서는 개인 특성에 따라 구직욕구에 차이가 나타났으며, 구직의사와 구직활동에도 차이가 있다는 것이 확인되었다[5]. 이 의미는 구직자의 개인 특성에 따라 구직욕구가 차이가 있는 것을 볼 수 있다. 한편 경력단절 여성의 재취업 욕구를 분석한 결과를 살펴보면, 구직효능감이 높을수록 구직행동을 더 많이 하는 경향이 있었고, 경제적 필요가 강한 여성일수록 구직행동을 더 많이 한 것으로 나타났다[6]. 이 결 과는 재취업을 원하는 경력단절 여성에게는 교육을 통한 구직효능감 강화가 필요하다고 판단된다.

구직효능감에 미치는 영향을 살펴보면 구직자의 사회적 지지가 구직효능감에 유의한 영향을 미 치는 것으로 확인되었다[7]. 또한 대학생을 대상으로 한 연구결과에도 사회적 지지수준을 높게 지 각할수록, 구직효능감이 높게 나타났다[8]. 이러한 결과는 구직자가 구직욕구가 부족할 때, 사회적 지지를 받으면 구직효능감 강화로 적극적인 구직행동을 할 수 있는 것으로 분석된다. 대부분의 연 구들이 대학졸업자이거나 중장년층 등 특정 연령대를 중심으로 연구가 진행되어 왔으며, 구직자 전체 연령에 대한 연구가 부족한 실정이다. 따라서 본 연구는 다양한 연령의 구직자의 사회적 지 지가 구직욕구에 미치는 영향이 어떠한지 연구가 필요하다.

또한 구직자의 직업기초능력 중에서 의사소통 과정이 중요한 것으로 나타났으며, 대학생의 의사 소통이 진로의식에 미치는 영향에서 의사소통은 진로의식에 정적 영향을 미친다고 하였으며[9], 간 호대학생의 의사소통 과정은 진로 자기효능감과 정적 관계를 갖는다고 보고하고 있다[10]. 결과적 으로 구직활동과 취업성공에 있어서 중요한 구직욕구에는 의사소통 과정이 중요한 영향력이 있음 을 설명하고 있다.

이상의 선행연구를 분석한 결과, 구직자의 사회적 지지와 의사소통 과정이 구직욕구에 영향을 미치는 요인으로 확인되었으며, 이들의 관계는 정적 관계를 유지하고 있음을 알 수 있었다. 하지만 선행연구에서는 특정 연령대를 중심으로 연구가 이루어졌으며, 사회적 지지가 구직욕구에 미치는 영향에 대한 의사소통 과정의 매개효과에 대한 연구는 매우 미흡한 실정이다. 따라서 본 연구에서 는 구직자의 사회적 지지, 구직욕구, 의사소통 과정 간의 영향 관계와 사회적 지지가 구직욕구에 미치는 영향에 대한 의사소통 과정의 매개효과를 연구함으로써 구직자의 구직욕구를 향상시킬 수 있는 방안과 구직행동 활성화에 대한 정책적인 기초자료를 제공하고자 한다.

\section{2 연구문제}

본 연구의 목적은 구직자의 사회적 지지, 구직욕구, 의사소통 과정 간의 영향 관계와 의사소통 과 정의 매개효과를 분석하는 것이다. 이에 대한 구체적인 연구문제는 다음과 같다.

1) 구직자가 지각한 사회적 지지가 구직욕구에 미치는 영향은 어떠한가? 
The Effect of Job Seeker's Perceived Social Support on Job Search Needs: Focusing on the Mediating Effect of Communication Process

2) 구직자가 지각한 사회적 지지가 의사소통 과정에 미치는 영향 어떠한가?

3) 구직자가 지각한 의사소통 과정이 구직욕구에 미치는 영향은 어떠한가?

4) 구직자의 사회적 지지가 구직욕구에 미치는 영향에 대해서 의사소통 과정의 매개효과는 어떠 한가?

\section{2. 연구방법}

\section{1 연구대상}

본 연구는 2018년 6월 1일부터 2018년 7월 31일까지 경상북도 00시 고용센터 이용자 230명을 대상 으로 조사하였다. 설문조사는 연구대상자에게 사전에 설문 취지에 대해서 충분히 설명한 후에 자 기기입식으로 실시하였다. 연구 자료는 총 220 부의 자료를 수집한 후에 연구 자료로 적절치 않은 설문지 14 부를 제외한 206부의 자료를 분석에 활용하였다.

\section{2 연구도구}

본 연구에 사용된 도구는 일반적 특성 7 문항, 사회적 지지 48 문항, 구직욕구 14 문항, 의사소통 과 정 12 문항, 총 81 문항으로 구성되어 있다. 일반적 특성에 관한 내용은 성별, 연령, 학력, 결혼상태, 가구당 월평균 소득, 실업기간, 실업횟수 등으로 구성하여 조사하였다. 고용복지플러스센터 이용자 의 사회적 지지를 측정하기 위해 박주연[11]이 사용한 사회적 지지 측정도구로 하위요인은 정서적 지지, 정보적 지지, 물질적 지지, 평가적 지지 영역의 문항을 리커트 5점 척도로 측정하였다. 구직 자가 지각한 구직욕구를 측정하기 위해 한국고용정보원[12]에서 개발한 구직욕구 측정도구로 적극 적인 구직활동과 일자리 수용 자세에 대한 문항을 리커트 5점 척도로 측정하였다. 구직자가 지각 한 의사소통 과정을 측정하기 위해 박주연[11]이 사용한 의사소통 과정 영역의 문항을 리커트 5점 척도로 측정하였다.

\section{3 신뢰도}

본 연구에 사용된 각 변수의 신뢰도 검증결과 의사소통 과정은 .750-.778, 의사소통 과정 .964, 구직 욕구의 신뢰도 .836으로 높게 나타났다. 각 측정도구의 신뢰도는 Cronbach's a값이 .60 이상으로 신뢰성을 확보하였기 때문에 신뢰도에 문제가 없다고 할 수 있다. 구체적인 신뢰도 검증결과는 [표 1]과 같다. 
[표 1] 주요 변수의 신뢰도

[Table 1] Reliability of Key Variables

\begin{tabular}{|c|c|c|}
\hline \multicolumn{2}{|c|}{ 구분 } & Cronbach's Alpha \\
\hline \multirow{4}{*}{ 의사소통 과정 } & 정서적 지지 & .778 \\
\hline & 정보적 지지 & .766 \\
\hline & 물질적 지지 & .750 \\
\hline & 평가적 지지 & .773 \\
\hline \multicolumn{2}{|c|}{ 의사소통 과정 } & .964 \\
\hline \multicolumn{2}{|c|}{ 구직욕구 } & .836 \\
\hline
\end{tabular}

\section{4 자료 처리 및 분석 방법}

연구를 위해 수집된 자료처리 및 분석 방법은 SPSS 22.0 프로그램을 사용해 유의수준 $5 \%$ 에서 검 증하였으며, 연구도구의 신뢰도 검증은 Cronbach's a의 계수를 사용하여 분석하였다. 구직자가 지 각한 일반적 특성은 빈도 분석을 실시하여 알아보았고, 측정변수의 분포를 분석하기 위해 기술통 계 분석을 실시하였으며, 측정변수간의 관계를 분석하기 위하여 상관 분석을 실시하였다. 구직자가 지각한 사회적 지지, 구직욕구, 의사소통 과정 간의 영향을 분석하기 위해 다중회귀 분석을 실시하 였다. 그리고 구직자가 지각한 사회적 지지가 구직욕구에 미치는 영향에 대한 의사소통 과정의 매 개효과를 분석하기 위해 Baron \& Kenny(1987)가 사용한 3단계 매개효과 분석을 실시하였으며, 통 계적 검증을 위하여 Sobel test를 실시하였다.

\section{3. 연구결과}

\section{1 인구사회학적 특성}

본 연구대상자의 인구사회학적 특성을 살펴보면, 구직자가 지각한 성별은 남자 77 명 $(37.46 \%)$, 여자 129 명 $(62.6 \%)$ 으로 여자의 비율이 높았으며, 연령은 30대가 77명(37.4\%)으로 가장 많았고, 40 대가 55 명 $(26.7 \%), 20$ 대가 48 명 $(23.3 \%), 50$ 대 이상이 26 명 $(12.6 \%)$ 순으로 나타났다. 학력은 고졸이 83 명 $(40.3 \%)$ 으로 가장 많았으며, 대학졸업이 57 명 $(27.7 \%)$, 전문대졸이 49 명 $(23.8 \%)$, 중졸 이하가 13 명 $(6.3 \%)$, 대학원 졸업 이상이 4 명 $(1.9 \%)$ 순으로 조사되었다. 결혼 상태는 기혼이 134 명 $65.0 \%)$ 으로 미혼 72 명 $(35.0 \%)$ 보다 더 많은 것으로 나타났다. 가구당 월평균 소득은 100 만원 이상 200 만원 미만 의 소득이 65 명 $31.6 \%)$ 으로 가장 많았으며, 200만원 이상 300 만원 미만의 소득이 64 명(31.0)으로 높 은 것으로 파악되었다. 구직자의 실업기간은 6 개월 미만이 136 명 $66.0 \%)$ 으로 가장 많았으며, 6 개월 
The Effect of Job Seeker's Perceived Social Support on Job Search Needs: Focusing on the Mediating Effect of Communication Process

이상-1년 미만이 32명(15.5\%), 5년 이상이 17명(8.3\%), 1년 이상 3년 미만이 12 명(5.8\%), 3년 이상 5 년 미만이 9명 $(4.4 \%)$ 순으로 조사되었다. 구직자의 실업횟수는 1-2회가 149 명 $(72.3 \%)$ 으로 가장 많았 으며, 3-4회가 34 명 $(16.5 \%), 5$ 회 이상이 23 명 $(12.2 \%)$ 으로 조사되었다. 구직자가 지각한 인구사회학적 특성에 대하여 살펴본 결과는 [표 2]와 같다.

[표 2] 인구사회학적 특성

[Table 2] Demographic and Sociological Characteristics

\begin{tabular}{|c|c|c|c|}
\hline \multirow{2}{*}{\multicolumn{2}{|c|}{ 구분 }} & \multicolumn{2}{|c|}{ 전체 $(\mathrm{N}=206)$} \\
\hline & & 빈도 & 비율(\%) \\
\hline \multirow{2}{*}{ 성별 } & 남자 & 77 & 37.4 \\
\hline & 여자 & 129 & 62.6 \\
\hline \multirow{4}{*}{ 연령 } & 20대 & 48 & 23.3 \\
\hline & 30대 & 77 & 37.4 \\
\hline & 40대 & 55 & 26.7 \\
\hline & 50대 이상 & 26 & 12.6 \\
\hline \multirow{5}{*}{ 학력 } & 중졸 이하 & 13 & 6.3 \\
\hline & 고졸 & 83 & 40.3 \\
\hline & 전문대졸 & 49 & 23.8 \\
\hline & 대학졸업 & 57 & 27.7 \\
\hline & 대학원 졸업 이상 & 4 & 1.9 \\
\hline \multirow{2}{*}{ 결혼 상태 } & 미혼 & 72 & 35.0 \\
\hline & 기혼 & 134 & 65.0 \\
\hline \multirow{7}{*}{ 가구당 월평균 소득 } & 전혀 없음 & 19 & 9.2 \\
\hline & 100만원 미만 & 9 & 4.3 \\
\hline & 100 만원 이상 200 만원 미만 & 65 & 31.6 \\
\hline & 200 만원 이상 300 만원 미만 & 64 & 31.0 \\
\hline & 300 만원 이상 400 만원 미만 & 26 & 12.6 \\
\hline & 400 만원 이상 500 만원 미만 & 11 & 5.3 \\
\hline & 500만원 이상 & 12 & 5.8 \\
\hline \multirow{5}{*}{ 실업기간 } & 6개월 미만 & 136 & 66.0 \\
\hline & 6개월 이상 1 년 미만 & 32 & 15.5 \\
\hline & 1년 이상 3년 미만 & 12 & 5.8 \\
\hline & 3년 이상 5년 미만 & 9 & 4.4 \\
\hline & 5년 이상 & 17 & 8.3 \\
\hline \multirow{3}{*}{ 실업횟수 } & 1-2회 & 149 & 72.3 \\
\hline & 3-4회 & 34 & 16.5 \\
\hline & 5회 이상 & 23 & 12.2 \\
\hline
\end{tabular}

\section{2 주요 변수에 대한 기술통계}

구직자가 지각한 주요 변수에 대한 측정 변수는 5 점 척도로 측정하였으며, 사회적 지지의 하위요 인인 물질적 지지 $(\mathrm{M}=3.04)$ 가 가장 높게 나타났으며, 정보적 지지 $(\mathrm{M}=2.85)$, 정서적 지지 $(\mathrm{M}=2.77)$, 평 가적 지지 $(\mathrm{M}=2.69)$ 의 순으로 사회적 지지는 전체의 평균보다 약간 낮은 것으로 나타났다. 의사소 통 과정 $(\mathrm{M}=2.46)$, 구직욕구 $(\mathrm{M}=2.80)$ 는 평균보다 낮은 수준으로 나타난 것을 알 수 있다. 구직자가 
지각한 주요 변수에 대한 기술통계를 살펴본 결과는 [표 3]과 같다.

[표 3] 주요 변수에 대한 기술통계

[Table 3] Descriptive Statistics for Major Variables

\begin{tabular}{|c|c|c|c|c|c|c|c|c|}
\hline & 구분 & $\mathrm{N}$ & 최소값 & 최대값 & M & SD & 왜도 & 첨도 \\
\hline \multirow{4}{*}{$\begin{array}{c}\text { 사회적 } \\
\text { 지지 }\end{array}$} & 정서적 지지 & 206 & 1.00 & 4.67 & 2.77 & .59 & .12 & .26 \\
\hline & 정보적 지지 & 206 & 1.17 & 5.00 & 2.85 & .60 & .23 & .60 \\
\hline & 물질적 지지 & 206 & 1.58 & 4.92 & 3.04 & .60 & .33 & .04 \\
\hline & 평가적 지지 & 206 & 1.00 & 4.83 & 2.69 & .63 & .28 & .56 \\
\hline \multicolumn{2}{|r|}{ 의사소통 과정 } & 206 & 1.00 & 5.00 & 2.46 & .79 & .61 & .53 \\
\hline \multicolumn{2}{|r|}{ 구직욕구 } & 206 & 1.18 & 4.55 & 2.80 & .60 & .02 & .05 \\
\hline
\end{tabular}

\section{3 변수 간의 상관관계}

구직자가 지각한 사회적 지지와 의사소통 과정, 구직욕구와의 관련성을 살펴본 결과, 사회적 지지 의 하위변수인 정서적 지지, 정보적 지지, 물질적 지지, 평가적 지지는 각각 높은 수준의 양의 상 관관계를 지니는 것으로 확인되었다(r=.603-r=.816, $\mathrm{p}<.001)$. 사회적 지지와 의사소통 과정은 양의 상관관계를 지니는 것으로 파악되었다 $(\mathrm{r}=.167-\mathrm{r}=0.476, \mathrm{p}<.05, \mathrm{p}<.001)$. 그리고 사회적 지지와 구직욕 구는 양의 상관관계를 지니는 것으로 파악되었다 $(\mathrm{r}=177-\mathrm{r}=0.348, \mathrm{p}<.05, \mathrm{p}<.001)$. 의사소통 과정과 구직욕구는 높은 수준의 양의 상관관계를 지니는 것으로 나타났다(r=.293, r=.285, p<.001). 이러한 결과는 각 상관계수의 값이 변수들 간의 양의 관계성이 통계적으로 유의함을 보여주고 있는 것이 다. 이에 대한 변수 간 상관관계를 분석한 결과는 [표 4]와 같다.

[표 4] 주요 변수 간의 상관관계

[Table 4] Correlation between Key Variables

\begin{tabular}{|c|c|c|c|c|c|c|c|}
\hline & \multirow{2}{*}{ 구분 } & \multicolumn{4}{|c|}{ 사회적 지지 } & \multirow{2}{*}{$\begin{array}{c}\text { 의사소통 } \\
\text { 과정 }\end{array}$} & \multirow{2}{*}{ 구직욕구 } \\
\hline & & 정서적 지지 & 정보적 지지 & 물질적 지지 & 평가적 지지 & & \\
\hline \multirow{4}{*}{$\begin{array}{c}\text { 사회적 } \\
\text { 지지 }\end{array}$} & 정서적 지지 & 1 & & & & & \\
\hline & 정보적 지지 & $.816^{* * *}$ & 1 & & & & \\
\hline & 물질적 지지 & $.662^{* * *}$ & $.717^{* * *}$ & 1 & & & \\
\hline & 평가적 지지 & $.754^{* * *}$ & $.741^{* * *}$ & $.603^{* * *}$ & 1 & & \\
\hline
\end{tabular}


The Effect of Job Seeker's Perceived Social Support on Job Search Needs: Focusing on the Mediating Effect of Communication Process

\begin{tabular}{ccccccc} 
의사소통 과정 & $.467^{* * *}$ & $.425^{* * *}$ & $.167^{*}$ & $.476^{* * *}$ & 1 & \\
구직욕구 & $.315^{* * *}$ & $.348^{* * *}$ & $.177^{*}$ & $.371^{* * *}$ & $.285^{* * *}$ & 1 \\
\hline
\end{tabular}

${ }^{*} \mathrm{p}<.05,{ }^{* * *} \mathrm{p}<.001$

\section{4 구직자가 지각한 사회적 지지가 구직욕구에 미치는 영향}

구직자가 지각한 사회적 지지가 구직욕구에 미치는 영향을 알아보기 위해 다중 회귀 분석을 실시 한 결과, 구직욕구에 대한 사회적 지지의 설명력을 의미하는 R2값이 .167로 나타나 전체 변동의 $16.7 \%$ 로 회귀모형을 설명하고 있다. 또한 D-W(Durbin Watson) 값이 1.944로 0과 4 사이에 존재하 며, 2에 가까워 자기상관이 존재하지 않았고, 공차한계는 0.1 이상, VIF 값은 10 이하로서 다중공선 성이 없는 것으로 나타났다. 모형에 대한 분산 분석 결과 추정된 회귀모형 $(\mathrm{F}=10.042, \mathrm{p}<.000)$ 은 통 계적으로 유의미한 것으로 나타났다. 사회적 지지의 하위요인별로 영향력을 살펴보면, 정보적 지지 $(\beta=.268, \mathrm{p}<.036)$, 평가적 지지 $(\beta=.277, \mathrm{p}<.008)$ 는 구직욕구에 유의한 양 $(+)$ 의 영향력을 미치는 것으 로 나타났다. 반면 사회적 지지의 하위요인인 물질적 지지 $(\beta=-.191, \mathrm{p}<.045)$ 요인은 유의한 음(-)의 영향력을 미치는 것으로 나타났다. 하지만 정서적 지지 $(\beta=.013, \mathrm{p}>.05)$ 는 구직욕구에 유의한 영향을 미치지 않는 것으로 나타났다. 이는 구직자가 지각한 사회적 지지의 하위요인인 정보적 지지, 평가 적 지지 요인이 높을수록 구직욕구가 높으며, 물질적 지지 요인이 높을수록 구직욕구가 낮다는 것 을 의미하는 것이다. 고용복지플러스센터 이용자의 사회적 지지가 구직욕구에 미치는 영향을 분석 한 결과는 [표 5]와 같다.

[표 5] 구직자가 지각한 사회적 지지가 구직욕구에 미치는 영향

[Table 5] Effect of Late Social Support on Job Seekers' Desire for Jobs

\begin{tabular}{|c|c|c|c|c|c|c|c|}
\hline \multirow{2}{*}{ 종속변수 } & \multirow{2}{*}{ 독립변수 } & \multicolumn{2}{|c|}{ 비표준화 계수 } & \multirow{2}{*}{$\begin{array}{c}\text { 표준화 계수 } \\
\beta\end{array}$} & \multirow{2}{*}{$\mathrm{t}$} & \multirow{2}{*}{$\mathrm{p}$} & \multirow{2}{*}{$\begin{array}{l}\text { 공차 } \\
\text { 한계 }\end{array}$} \\
\hline & & B & 표준오차 & & & & \\
\hline \multirow{5}{*}{ 구직욕구 } & 상수 & 1.876 & .212 & & 8.866 & .000 & \\
\hline & 정서적 지지 & .013 & .123 & .013 & .107 & .915 & .279 \\
\hline & 정보적 지지 & .267 & .126 & .268 & $2.113^{*}$ & .036 & .257 \\
\hline & 물질적 지지 & -.190 & .094 & -.191 & $-2.020^{*}$ & .045 & .464 \\
\hline & 평가적 지지 & .261 & .098 & .277 & $2.659^{* *}$ & .008 & .381 \\
\hline \multicolumn{8}{|c|}{$\mathrm{R}^{2}=.167$, 수정된 $\mathrm{R}^{2}=.150$} \\
\hline \multicolumn{8}{|c|}{$\mathrm{F}=10.042, \mathrm{P}=.000$, Durbin-Watson $=1.944$} \\
\hline
\end{tabular}

${ }^{*} \mathrm{p}<.05,{ }^{* *} \mathrm{p}<.01,{ }^{* * *} \mathrm{p}<.001$ 
구직자가 지각한 사회적 지지가 의사소통 과정에 미치는 영향을 알아보기 위하여 다중 회귀 분석 을 실시한 결과, 의사소통 과정에 대한 사회적 지지의 설명력을 의미하는 R2값이 .320으로 나타나 전체 변동의 $32.0 \%$ 로 회귀모형을 설명하고 있다. 또한 D-W(Durbin Watson) 값이 1.771 로 0 과 4 사이에 존재하며, 2에 가까워 자기상관이 존재하지 않았고, 공차한계는 0.1 이상, VIF 값은 10 이하 로서 다중공선성이 없는 것으로 나타났다. 모형에 대한 분산 분석 결과 추정된 회귀모형 $(\mathrm{F}=23.674$, $\mathrm{p}<.000)$ 은 통계적으로 유의미한 것으로 나타났다. 사회적 지지의 하위요인별로 영향력을 살펴보면, 정서적 지지 $(\beta=.306, \mathrm{p}<.006)$, 평가적 지지 $(\beta=.317, \mathrm{p}<.001)$ 는 의사소통 과정에 유의한 양 $(+)$ 의 영향 력을 미치는 것으로 나타났다. 반면 사회적 지지의 하위요인인 물질적 지지 $(\beta=-.378, p<.000)$ 요인 은 유의한 음(-)의 영향력을 미치는 것으로 나타났다. 하지만 정보적 지지 $(\beta=.211, p>.05)$ 는 의사소 통 과정에 유의한 영향을 미치지 않는 것으로 나타났다. 이는 구직자가 지각한 사회적 지지의 하 위요인인 정서적 지지, 평가적 지지 요인이 높을수록 의사소통 과정이 높으며, 물질적 지지 요인이 높을수록 의사소통 과정이 낮다는 것을 의미하는 것이다. 고용복지플러스센터 이용자의 사회적 지 지가 의사소통 과정에 미치는 영향을 분석한 결과는 [표 6]과 같다.

[표 6] 구직자가 지각한 사회적 지지가 의사소통 과정에 미치는 영향

[Table 6] The Effect of Social Support Perceived by Job seekers on Communication Process

\begin{tabular}{|c|c|c|c|c|c|c|c|}
\hline \multirow{2}{*}{ 종속변수 } & \multirow{2}{*}{ 독립변수 } & \multicolumn{2}{|c|}{ 비표준화 계수 } & \multirow{2}{*}{$\frac{\text { 표준화 계수 }}{\beta}$} & \multirow{2}{*}{$\mathrm{t}$} & \multirow{2}{*}{$\mathrm{p}$} & \multirow{2}{*}{$\begin{array}{l}\text { 공차 } \\
\text { 한계 }\end{array}$} \\
\hline & & B & 표준오차 & & & & \\
\hline \multirow{5}{*}{$\begin{array}{c}\text { 의사소통 } \\
\text { 과정 }\end{array}$} & 상수 & .998 & .253 & & 3.939 & .000 & \\
\hline & 정서적 지지 & .407 & .147 & .306 & $2.776^{* *}$ & .006 & .279 \\
\hline & 정보적 지지 & .279 & .151 & .211 & 1.842 & .067 & .257 \\
\hline & 물질적 지지 & -.499 & .113 & -.378 & $-4.424^{* * *}$ & .000 & .464 \\
\hline & 평가적 지지 & .395 & .118 & .317 & $3.361^{* *}$ & .001 & .381 \\
\hline \multicolumn{8}{|c|}{$\mathrm{R}^{2}=.320$, 수정된 $\mathrm{R}^{2}=.307$} \\
\hline \multicolumn{8}{|c|}{$\mathrm{F}=23.674, \mathrm{P}=.000$, Durbin-Watson=1.771 } \\
\hline
\end{tabular}

${ }^{*} \mathrm{p}<.05,{ }^{* *} \mathrm{p}<.01,{ }^{* * *} \mathrm{p}<.001$

\section{6 구직자가 지각한 의사소통 과정이 구직욕구에 미치는 영향}

구직자가 지각한 의사소통 과정이 구직욕구에 미치는 영향을 알아보기 위하여 다중 회귀 분석을 실시한 결과, 구직욕구에 대한 의사소통 과정의 설명력을 의미하는 R2값이 .081로 나타나 전체 변 
The Effect of Job Seeker's Perceived Social Support on Job Search Needs: Focusing on the Mediating Effect of Communication Process

동의 $8.1 \%$ 로 회귀모형을 설명하고 있다. 또한 D-W(Durbin Watson) 값이 2.013으로 0과 4 사이에 존재하며, 2에 가까워 자기상관이 존재하지 않았고, 공차한계는 0.1 이상, VIF 값은 10 이하로서 다 중공선성이 없는 것으로 나타났다. 모형에 대한 분산 분석 결과 추정된 회귀모형 $(\mathrm{F}=18.036, \mathrm{p}<.000)$ 은 통계적으로 유의미한 것으로 나타났다. 의사소통 과정 $(\beta=.285, \mathrm{p}<.000)$ 은 구직욕구에 유의한 양 $(+)$ 의 영향력을 미치는 것으로 나타났다. 이는 구직자가 지각한 의사소통 과정이 높을수록 구직욕 구가 높다는 것을 의미하는 것이다. 고용복지플러스센터 이용자의 의사소통 과정이 구직욕구에 미 치는 영향을 분석한 결과는 [표 7]과 같다.

[표 7] 구직자가 지각한 사회적 지지가 의사소통 과정에 미치는 영향

[Table 7] The Effect of Social Support Perceived by Job seekers on Communication Process

\begin{tabular}{|c|c|c|c|c|c|c|c|}
\hline \multirow{2}{*}{ 종속변수 } & \multirow{2}{*}{ 독립변수 } & \multicolumn{2}{|c|}{ 비표준화 계수 } & 표준화 계수 & \multirow{2}{*}{$\mathrm{t}$} & \multirow{2}{*}{$\mathrm{p}$} & \multirow{2}{*}{$\begin{array}{l}\text { 공차 } \\
\text { 한계 }\end{array}$} \\
\hline & & B & 표준오차 & $\beta$ & & & \\
\hline \multirow{2}{*}{ 구직욕구 } & 상수 & 2.267 & .131 & & 17.304 & .000 & \\
\hline & 의사소통 과정 & .215 & .051 & .285 & $4.247^{* * *}$ & .000 & 1.000 \\
\hline \multicolumn{8}{|c|}{$\mathrm{R}^{2}=.081$, 수정된 $\mathrm{R}^{2}=.077$} \\
\hline \multicolumn{8}{|c|}{$\mathrm{F}=18.036, \mathrm{P}=.000$, Durbin-Watson=2.013 } \\
\hline
\end{tabular}

${ }^{*} \mathrm{p}<.05,{ }^{* *} \mathrm{p}<.01,{ }^{* * *} \mathrm{p}<.001$

3.7 구직자가 지각한 사회적 지지가 구직욕구에 미치는 영향에 대한 의사소통 과정의 매개효 과

구직자가 지각한 사회적 지지가 구직욕구에 미치는 영향에 대해서 의사소통 과정의 매개효과를 분 석하기 위하여 Baron \& Kenny(1987)가 사용한 3단계 매개 효과 분석을 실시하였다. 매개효과가 존재하기 위해서는 3 가지의 다음과 같은 조건을 충족하여야 한다. 첫째, 독립변수는 매개변수에 영 향을 미쳐야 한다. 둘째, 독립변수는 종속변수에 영향을 미쳐야 한다. 셋째, 독립변수와 매개변수를 동시에 투입하여 종속변수에 미치는 영향에서 매개변수는 종속변수에 반드시 영향을 미쳐야 하며, 독립변수가 영향을 미치지 않으면 완전매개효과, 독립변수가 종속변수에 영향을 미치며 2단계보다 영향력이 감소하면 부분 매개 효과를 보인다고 할 수 있다. 또한 통계적 검증을 위하여 Sobel test 를 실시한 결과는 다음과 같다.

구직자가 지각한 정서적 지지가 구직욕구에 미치는 영향에 대해서 의사소통 과정의 매개효과를 

분석한 결과, 1 단계에서는 정서적 지지가 의사소통 과정에 양(+)의 영향을 미치는 것으로 나타났다 $(\beta=.467, \mathrm{p}<.001) .2$ 단계에서는 정서적 지지가 구직욕구에 양 $(+)$ 의 영향을 미치는 것으로 나타났다 $(\beta=.315, \mathrm{p}<.001)$. 3 단계에서는 의사소통 과정 $(\beta=.176, \mathrm{p}<.05)$ 이 구직욕구에 양 $(+)$ 의 영향을 미치고 있으며, 정서적 지지 $(\beta=.233, \mathrm{p}<.01)$ 도 구직욕구에 양 $(+)$ 의 영향을 미치며, 2 단계보다 영향력이 감소 한 것으로 나타났고, sobel test 결과, $\mathrm{z}=2.266$ 으로 통계적으로 매개효과가 유의미한 것으로 나타났 다. 즉 구직자가 지각한 정서적 지지가 구직욕구에 미치는 영향에 대해서 의사소통 과정은 부분 매개 효과를 보이고 있었으며, 분석한 결과는 [표 8]과 같다.

[표 8] 구직자가 지각한 정서적 지지가 구직욕구에 미치는 영향에 대한 의사소통 과정 매개효과 [Table 8] The Intermediation Effect of Communication Process on the Effect of Perceived Emotional Support on Job-seeking Desire

\begin{tabular}{|c|c|c|c|c|c|c|c|}
\hline \multirow{2}{*}{ 종속변수 } & \multirow{2}{*}{ 독립변수 } & \multicolumn{2}{|c|}{ 비표준화 계수 } & \multirow[t]{2}{*}{ 표준화 계수 } & \multirow{2}{*}{$\mathrm{R} 2$} & \multirow{2}{*}{ F } & \multirow{2}{*}{$t$} \\
\hline & & B & 표준오차 & & & & \\
\hline \multirow{2}{*}{$\begin{array}{c}\text { 의사소통 } \\
\text { 과정 }\end{array}$} & (상수) & .742 & .233 & & \multirow{2}{*}{.218} & \multirow{2}{*}{$56.913^{* * *}$} & 3.179 \\
\hline & 정서적 지지 & .622 & .082 & .467 & & & $7.544^{* * *}$ \\
\hline \multirow{2}{*}{ 구직욕구 } & (상수) & 1.921 & .189 & & \multirow{2}{*}{.099} & \multirow{2}{*}{$22.458^{* * *}$} & 10.160 \\
\hline & 정서적 지지 & .317 & .067 & .315 & & & $4.739^{* * *}$ \\
\hline \multirow{3}{*}{ 구직욕구 } & (상수) & 1.822 & .192 & & \multirow{3}{*}{.124} & \multirow{3}{*}{$14.302^{* * *}$} & 9.514 \\
\hline & 정서적 지지 & .234 & .075 & .233 & & & $3.129^{* *}$ \\
\hline & 의사소통 & .133 & .056 & .176 & & & $2.374^{*}$ \\
\hline
\end{tabular}

Sobel test : $\mathrm{z}=2.266^{*}$

${ }^{*} \mathrm{p}<.05,{ }^{* *} \mathrm{p}<.01,{ }^{* * *} \mathrm{p}<.001$

구직자가 지각한 정보적 지지가 구직옥구에 미치는 영향에 대해서 의사소통 과정의 매개효과를 분석한 결과, 1 단계에서는 정보적 지지가 의사소통 과정에 양(+)의 영향을 미치는 것으로 나타났다 $(\beta=.425, \mathrm{p}<.001) .2$ 단계에서는 정보적 지지가 구직욕구에 양 $(+)$ 의 영향을 미치는 것으로 나타났다 $(\beta=.348, \mathrm{p}<.001)$. 3 단계에서는 의사소통 과정 $(\beta=.167, \mathrm{p}<.05)$ 이 구직욕구에 양 $(+)$ 의 영향을 미치고 있으며, 정보적 지지 $(\beta=.277, \mathrm{p}<.001)$ 도 구직욕구에 양 $(+)$ 의 영향을 미치며, 2 단계보다 영향력이 감 소한 것으로 나타났고, sobel test 결과, $\mathrm{z}=2.202$ 로 통계적으로 매개효과가 유의미한 것으로 나타났 다. 즉 구직자가 지각한 정보적 지지가 구직욕구에 미치는 영향에 대해서 의사소통 과정은 부분 매개 효과를 보이고 있었으며, 분석한 결과는 [표 9]와 같다. 
The Effect of Job Seeker's Perceived Social Support on Job Search Needs: Focusing on the Mediating Effect of Communication Process

[표 9] 구직자가 지각한 정보적 지지가 구직욕구에 미치는 영향에 대한 의사소통 과정 매개효과

[Table 9] Intermediation Effect of Communication Process on the Effect of Perceptual Information Support on Job-seeking Desire

\begin{tabular}{|c|c|c|c|c|c|c|c|}
\hline \multirow{2}{*}{ 종속변수 } & \multirow{2}{*}{ 독립변수 } & \multicolumn{2}{|c|}{ 비표준화 계수 } & 표준화 계수 & \multirow{2}{*}{$\mathrm{R} 2$} & \multirow{2}{*}{ F } & \multirow{2}{*}{$t$} \\
\hline & & B & 표준오차 & 베타 & & & \\
\hline \multirow{2}{*}{$\begin{array}{c}\text { 의사소통 } \\
\text { 과정 }\end{array}$} & (상수) & .869 & .243 & & \multirow{2}{*}{.180} & \multirow{2}{*}{$44.904^{* * *}$} & 3.572 \\
\hline & 정보적 지지 & .560 & .084 & .425 & & & $6.701^{* * *}$ \\
\hline \multirow{2}{*}{ 구직욕구 } & (상수) & 1.811 & .190 & & \multirow{2}{*}{.121} & \multirow{2}{*}{$28.073^{* * *}$} & 9.528 \\
\hline & 정보적 지지 & .346 & .065 & .348 & & & $5.298^{* * *}$ \\
\hline \multirow{3}{*}{ 구직욕구 } & (상수) & 1.701 & .194 & & \multirow{3}{*}{.144} & \multirow{3}{*}{$17.069^{* * *}$} & 8.777 \\
\hline & 정보적 지지 & .275 & .071 & .277 & & & $3.857^{* * *}$ \\
\hline & 의사소통 & .126 & .054 & .167 & & & $2.335^{*}$ \\
\hline
\end{tabular}

Sobel test : $\mathrm{z}=2.202^{*}$

${ }^{*} \mathrm{p}<.05,{ }^{* * *} \mathrm{p}<.001$

구직자가 지각한 물질적 지지가 구직욕구에 미치는 영향에 대해서 의사소통 과정의 매개효과를 분석한 결과, 1 단계에서는 물질적 지지가 의사소통 과정에 양 $(+)$ 의 영향을 미치는 것으로 나타났다 $(\beta=.167, p<.05)$. 2 단계에서는 물질적 지지가 구직욕구에 양 $(+)$ 의 영향을 미치는 것으로 나타났다( $\beta$ $=.177, \mathrm{p}<.05)$. 3 단계에서는 의사소통 과정 $(\beta=.263, \mathrm{p}<.001)$ 이 구직욕구에 양 $(+)$ 의 영향을 미치고 있 으며, 물질적 지지( $\beta=.134, p<.05)$ 도 구직욕구에 양 $(+)$ 의 영향을 미치며, 2 단계보다 영향력이 감소한 것으로 나타났고, sobel test 결과, $\mathrm{z}=2.058$ 로 통계적으로 매개효과가 유의미한 것으로 나타났다. 즉 구직자가 지각한 물질적 지지가 구직욕구에 미치는 영향에 대해서 의사소통 과정은 부분 매개 효 과를 보이고 있었으며, 분석한 결과는 [표 10]과 같다.

[표 10] 구직자가 지각한 물질적 지지가 구직욕구에 미치는 영향에 대한 의사소통 과정 매개효과

[Table 10] Intermediation Effect of Communication Process on the Effect of Perceptual Material Support on Job-seeking Desire

\begin{tabular}{|c|c|c|c|c|c|c|c|}
\hline \multirow{2}{*}{ 종속변수 } & \multirow{2}{*}{ 독립변수 } & \multicolumn{2}{|c|}{ 비표준화 계수 } & 표준화 계수 & \multirow{2}{*}{$\mathrm{R} 2$} & \multirow{2}{*}{$\mathrm{F}$} & \multirow{2}{*}{$\mathrm{t}$} \\
\hline & & B & 표준오차 & 베타 & & & \\
\hline \multirow{2}{*}{$\begin{array}{c}\text { 의사소통 } \\
\text { 과정 }\end{array}$} & (상수) & 1.792 & .283 & & \multirow{2}{*}{.028} & \multirow{2}{*}{$5.872^{*}$} & 6.341 \\
\hline & 물질적 지지 & .221 & .091 & .167 & & & $2.423^{*}$ \\
\hline \multirow{2}{*}{ 구직욕구 } & (상수) & 2.259 & .213 & & \multirow{2}{*}{.032} & \multirow{2}{*}{$6.635^{*}$} & 10.612 \\
\hline & 물질적 지지 & .177 & .069 & .177 & & & $2.576^{*}$ \\
\hline \multirow{3}{*}{ 구직욕구 } & (상수) & 1.904 & .225 & & \multirow{3}{*}{.099} & \multirow{3}{*}{$11.098^{* * *}$} & 8.452 \\
\hline & 물질적 지지 & .133 & .067 & .134 & & & $1.976^{*}$ \\
\hline & 의사소통 & .198 & .051 & .263 & & & $3.886^{* * *}$ \\
\hline
\end{tabular}

Sobel test : $z=2.058^{*}$

${ }^{*} \mathrm{p}<.05,{ }^{* * *} \mathrm{p}<.001$ 
구직자가 지각한 평가적 지지가 구직욕구에 미치는 영향에 대해서 의사소통 과정의 매개효과를 분석한 결과, 1 단계에서는 평가적 지지가 의사소통 과정에 양 $(+)$ 의 영향을 미치는 것으로 나타났다 $(\beta=.227, p<.001)$. 2 단계에서는 평가적 지지가 구직욕구에 양 $(+)$ 의 영향을 미치는 것으로 나타났다 $(\beta=.371, \mathrm{p}<.001)$. 3 단계에서는 의사소통 과정 $(\beta=.140, \mathrm{p}>.05)$ 이 구직욕구에 영향을 미치고 있지 못 한 것으로 나타나고 있어 구직자가 지각한 평가적 지지가 구직욕구에 미치는 영향에 대해서 의사 소통 과정은 매개효과를 보이지 않으며, 분석한 결과는 [표 11]과 같다.

[표 11] 구직자가 지각한 평가적 지지가 구직욕구에 미치는 영향에 대한 의사소통 과정 매개효과 [Table 11] Intermediation Effect of Communication Process on the Effect of the Appraisal Support Perceived by Job seekers on Job-seeking Desire

\begin{tabular}{|c|c|c|c|c|c|c|c|}
\hline \multirow{2}{*}{ 종속변수 } & \multirow{2}{*}{ 독립변수 } & \multicolumn{2}{|c|}{ 비표준화 계수 } & \multirow[t]{2}{*}{ 표준화 계수 } & \multirow{2}{*}{$\mathrm{R} 2$} & \multirow{2}{*}{$\mathrm{F}$} & \multirow{2}{*}{$\mathrm{t}$} \\
\hline & & B & 표준오차 & & & & \\
\hline \multirow{2}{*}{$\begin{array}{c}\text { 의사소통 } \\
\text { 과정 }\end{array}$} & (상수) & .866 & .212 & & \multirow{2}{*}{.227} & \multirow{2}{*}{$59.886^{* * *}$} & 4.083 \\
\hline & 평가적 지지 & .594 & .077 & .476 & & & $7.739^{* * *}$ \\
\hline \multirow{2}{*}{ 구직욕구 } & (상수) & 1.857 & .169 & & \multirow{2}{*}{.138} & \multirow{2}{*}{$32.604^{* * *}$} & 10.987 \\
\hline & 평가적 지지 & .350 & .061 & .371 & & & $5.710^{* * *}$ \\
\hline \multirow{3}{*}{ 구직욕구 } & (상수) & 1.766 & .175 & & \multirow{3}{*}{.153} & \multirow{3}{*}{$18.325^{* * *}$} & 10.108 \\
\hline & 평가적 지지 & .287 & .069 & .305 & & & $4.145^{* * *}$ \\
\hline & 의사소통 & .106 & .055 & .140 & & & 1.905 \\
\hline
\end{tabular}

$* * * p<.001$

\section{4. 결론 및 제언}

본 연구에서는 구직자의 사회적 지지가 의사소통과 구직욕구에 미치는 영향에 대하여 파악하였다. 분석결과를 토대로 구체적으로 논의하면 다음과 같다.

첫째, 구직자가 지각한 사회적 지지가 구직욕구에 미치는 영향을 분석한 결과, 사회적 지지의 정보적 지지, 평가적 지지는 구직욕구에 긍정적인 영향력을 미치는 것으로 나타났다. 반면 사회적 지지의 물질적 지지 요인은 부정적인 영향력을 미치는 것으로 나타났다. 이러한 결과는 사회적 지 지가 구직욕구에 영향을 미친다는 선행연구들과 부분적으로 유사하게 나타났다.[5][9], 구직자가 지 각한 사회적 지지의 정보적 지지, 평가적 지지가 높을수록 구직욕구가 높으며, 물질적 지지 요인이 높을수록 구직욕구가 낮다는 것을 의미하는 것이다. 즉 구직자의 구직욕구를 향상시키기 위해서는 정보적 지지와 평가적 지지는 지속적으로 증가시켜야 한다고 볼 수 있다. 


\section{The Effect of Job Seeker's Perceived Social Support on Job Search Needs: Focusing on the Mediating Effect of Communication Process}

둘째, 구직자가 지각한 사회적 지지가 의사소통 과정에 미치는 영향을 분석한 결과, 사회적 지 지의 정서적 지지, 평가적 지지는 의사소통 과정에 긍정적인 영향력을 미치는 것으로 나타났다. 반 면 사회적 지지의 물질적 지지 요인은 부정적인 영향력을 미치는 것으로 나타났다. 이러한 결과는 사회적 지지와 의사소통과 정적 상관관계를 갖는 것으로 나타났다는 신재욱과 신민철(2013)의 연 구결과는 본 연구를 지지하는 것으로[13], 구직자가 지각한 사회적 지지의 하위요인인 정서적 지 지, 평가적 지지 요인이 높을수록 의사소통 과정이 높으며, 물질적 지지 요인이 높을수록 의사소통 과정이 낮다는 것을 의미하는 것이다. 즉 구직자의 의사소통 과정을 향상시키기 위해서는 사회적 지지 향상이 선행되어야 함을 의미한다.

셋째, 구직자가 지각한 의사소통 과정이 구직욕구에 미치는 영향을 분석한 결과, 의사소통 과정 은 구직욕구에 긍정적인 영향력을 미치는 것으로 나타났다. 이러한 결과는 의사소통 과정과 구직 옥구 간의 관계가 있다는 선행연구와 유사한 결과로서[11][12], 이는 구직자가 지각한 의사소통 과 정이 높을수록 구직욕구가 높다는 것을 의미하는 것이다. 구직욕구의 향상은 의사소통 과정에 의 해 영향을 받기 때문에 의사소통 과정을 향상시킬 수 있는 방안이 마련되어야 할 것이다.

넷째, 구직자의 사회적 지지가 구직욕구에 미치는 영향에 대해서 의사소통 과정의 매개효과를 분석한 결과, 구직자의 정서적 지지, 정보적 지지, 물질적 지지가 구직욕구에 미치는 영향에 대해 서 의사소통 과정은 부분 매개 효과를 보였다. 이와 같은 결과는 구직자의 구직옥구는 사회적 지 지에 의해서만 결정되는 것이 아니라 의사소통 과정도 중요한 요인이라는 것을 의미한다. 즉 구직 자의 구직욕구를 향상시키기 위해서는 사회적 지지와 의사소통 과정을 향상시킬 수 있도록 정책 적, 제도적인 방안이 선행되어야 할 것이다.

이상의 논의된 바를 정리해보면, 고용서비스 측면에서 다양한 구직문제를 해결하기 위한 직접적 인 방법으로 고용복지플러스센터를 통한 구직자의 적극적인 구직행동이 필요하다. 또한 구직욕구 향상을 위해서 구직자의 사회적 지지와 의사소통 과정을 향상시킬 수 있도록 정부와 지자체에서 정책적, 제도적인 방안을 마련해야 할 것이다. 즉 구직자에게 있어서 구직욕구를 증가시킬 수 있는 사회적 지지 향상과 의사소통 증진 프로그램 등의 개발이 필요하다. 따라서 본 연구의 시사점은 지금까지 구직자의 구직행동과 관련한 연구에서는 주로 구직의도, 구직 효능감, 구직행동에 미치는 영향에 관한 연구 등이 있었으나, 본 연구에서는 사회적 지지가 구직욕구에 미치는 영향을 파악하 고, 특히 의사소통 과정이 사회적 지지와 구직욕구에서 매개효과를 분석하는데 의의가 있다고 본 다. 향후 다양한 연령대의 구직자를 대상으로 의사소통 과정과 구직욕구 향상에 대해 심층적인 연 구가 요구된다.

\section{References}


[2] The Hankook Ilbo, https://www.hankookilbo.com, Mar 26 (2020)

[3] Lee Sook-ja, The Effects of Social Support Perceived by Career-interrupted Women On Career Preparation Behavior: Focus on Mediating Effects of Career Decision Self-efficacy, Journal of the Korea Society of Computer and Information, (2019), Vol.24, No.12, pp.109-117, DOI: 10.9708/jksci.2019.24.12.109

[4] Kim Na-rae, Hong A-jung, The effects of social support of middle-aged job seekers on job seeking behavior and the mediating effects of disposal learning, Continuing Education Studies, (2016), Vol.22, No.2, pp.109-136.

[5] Shin Yeon-ha, Lee Dong-myeong, Analysis of the Differences in Re-employment Need on the Individual Characteristic of Career Interrupted Woman, Journal of the Korea Contents Association, (2017), Vol.17, No.9, pp.310-323, DOI: 10.5392/JKCA.2017.17.09.310

[6] Lee Bora, Song Soo-Jin, Ji Su-in, Kang Jung-Hoon, Factors Associated with Career-disrupted Women's Re-employment Motivation, The Korean Journal of Human Development, (2019), Vol.26, No.1, pp.177-199, DOI: $10.15284 /$ kjhd.2018.26.1.177

[7] Cho Jung-hyun, Park Jong-un, Won Hyo-heon, The effects of job seekers' social support and self-efficacy on job seeking efficacy, Journal of Fisheries and Marine Sciences Education, (2018), Vol.30, No.3, pp.796-806, DOI: $10.13000 / J F M S E .2018 .06 .30 .3 .796$

[8] Bae Eul-gyu, Kim Dae-young, Lee Yun-jin, Kang Sun-hee, The Moderated Mediation Effect of Career Planning on the Relationship among Social Support, Downward Employment Intention, and Active Job Seeking Behavior of Career Discontinued Women, Andragogy Today: Interdisciplinary Journal of Adult \& Continuing Education, (2020), Vol.23, No.1, pp.1-29, DOI: 10.22955/ace.23.1.202002.1

[9] Kim Hee-soo, Moon Seung-tae, The influences of communications with parents and career decision self-efficacy on career conscientiousness among college students, The Journal of Career Education Research, (2011), Vol.24, No.2, pp.183-195, UCI: G704-001285.2011.24.2.011

[10] Shim Jeong-shin, Relationship among Communication Competence, Career Decision-Making Self-Efficacy, and Career Barriers in Nursing Students, Art Humanities and Social Convergence Multimedia Journal, (2017), Vol.7, No.11, pp.147-158, DOI: 10.35873/ajmahs.2017.7.11.015

[11] J. Y. Park, The Impact of family Resilience and Social Support affecting the psychological welfare of single parents and their adolescents, Department of Family Environment \& Welfare Graduate School of Chonnam National University, Doctoral Thesis, (2011)

[12] Job Needs Diagnostic Test Development Research Report, Korea Employment Information Service, (1999)

[13] Shin Jae-wook, Shin Min-cheol, A study on the positive effects of self-esteem and social support on interpersonal communication and the tendency to addiction to mobile communication services, Social Science Research, (2013), Vol.29, No.3, pp.329-360, UCI: G704-001638.2013.29.3.018 